\title{
The Present Situation of Fairness in
}

\section{Elementary Education}

\author{
$\mathrm{Ke} \mathrm{Li}$ \\ College of Education Science, Henan University \\ Room 457 in No.16 Dormitory, Jinming School District, Kaifeng 475001, China \\ E-mail: yuanxuecoco2003@yahoo.com.cn
}

\begin{abstract}
With the development of the society, there is a widespread public concern about the problem of "fairness of education", which possesses the prominent characteristics of the times in different educational stage. This paper views from the angle of "elementary education", then carry out analysis of the problem of fairness in starting point, educational process and the result, and gradually spread out the reason for this phenomenon. At the end of this paper, it puts forward some proposals about how to strengthen the fairness of education.
\end{abstract}

Keywords: Elementary education, Fairness

\section{Introduction}

In this modern world, education is not only an essential prerequisite of the individual's survival and improvement, but a forceful tool to pull the society goes forward. The fairness of education is a part of the fairness of society, also the reflection of it in the educational area. Therefore, the fairness of education is limited by many factors, such as the social political policy, economic policy, culture development, social classes and population development. The unfairness of the society leads to the phenomenon of unfairness of education; meanwhile, their interaction will only aggravate the both sides even further. As it is known that the disparity in all works of the social development, there prop up various problems of the unfairness of education. Thus, how to equalize the education becomes the hot topic in people's discussion.

\subsection{Fairness of Education in China}

With the promulgation and execution of the law, called "Nine-year of compulsory education", people can see the progress our elementary education has made evidently. According to some data, by the end of 1977, six provinces had achieved the goal of the law. About $65 \%$ of the population had received the compulsory education, the ratio of children entering the elementary school was $98 \%$, the junior high school students aged $12 \sim 14$ was $87 \%$. Generally speaking, the country had popularized the basic education, but in fact, the gap was great. Take the data from the report about the ratio of compulsory education's popularization for example: the western part was $96.47 \%$, the middle part was $81.87 \%$, and the eastern part was $42.26 \%$. When the developed area along the coastal had nearly popularized the education of the junior high school, $2 / 3$ of the western part hadn't met the standard, and the poor minority there hadn't popularized the elementary education. Therefore, the disparity of education in different area was obviously great. We can analyze it from the starting point, process and result.

\subsubsection{Fairness in starting point}

It indicts that everyone can enjoy the opportunity of receiving education. According to the law of the compulsory education, all the children that are of the right age own the right of being educated, and their parents have the obligation to guarantee them to complete the compulsory education, but influenced by the inherent quality, facility, environment, economy situation, the education's scale and standard, so many unfair cases happened frequently. This phenomenon could be displayed by the difference of the ratio of entering school and drop school between different areas, the way of recruiting students, and more boys than girls in school, all these facts can reflect the unfairness of education.

The compulsory education has been regarded as a special gift the country gives to all the children. Nevertheless, there are a great number of children have no approach to this gift. Data from1983 to1990 displayed that the number of illiteracy in China was 11 million; average number was 137.5 per year. The ratio and scale was reduced from the 1970s, but it was still a large group. Recently, the essential reason for the phenomenon of illiteracy has been the weakness of the elementary education's procedures. One explanation is that many right age children can't enter school; another is that some of school children can't continue to afford their studies; they quit school in the middle of the term, because of various of reasons.

Although the ratio of entering school increase than before and the education in the country has improved greatly, the unfairness in education still is a serious concern, and takes place often. Take the ratio of entering school between city and 
country as an example in 1995: the enrolment rate of the nine-year compulsory education in rural area took up $89 \%$ in all the right age children. In the whole country, ratio of the students being in school was far less than $80 \%$, for example, the rate of elementary school was $70.5 \%$, and the junior high school was $57.1 \%$. Let's look at the present situation of the secondary school in 1998 between the rural area and city area; students from the countryside took up 50\% in the junior middle school, while only a quarter in the senior middle school. The disparity between the city and rural rose by four-percentage points from 1995 to 1998.

View it from the point of the school dropout, the situation was also serious. According to an official source, during 39 years from 1950 to 1988, the overall number of the dropout in elementary school is 307.834 million, averaged 789.33 persons decreased per year. The dropout rate was 7.7\%, which means one student quitted school out of 2.5. Meanwhile, dropout rate in junior high school rose continually. The problem of the little girls' right in compulsory education was a great concern. It has been reported that the dropout rate was cause by the little girls on general. Little girls have less opportunity to continue their studies than boys. The female illiteracy took up 49\% of the total number. In 1997, some related research showed that in the compulsory education stage, if the family was faced dropout, most parents would show favor to the boys, in this circumstance, the scale of sexual distinction would incline to boys, who were favored. Compared with them, it was nearly impossible for the little girl to enjoy this fortune, while they easily became the sacrifice of dropout. In the great majority of cases, they were deprived of their political rights for education.

For a long time, the society placed undue emphasis on the proportion of students admitted to school of a higher level. Thus, the society only paid great attention to the key school, while ignoring the ordinary schools. As a result of this phenomenon, there started a school-collecting craze. Of course, the existence of the key school is above suspicious, and it's not corresponded to reality to let the parents show no concerns to them.

In order to avoid the phenomenon that the key schools are crowed with students, while the ordinary schools only recruit few numbers of students, most of the provinces adopt the way that children at the right age are supposed to attend school in the neighborhood. However, numerous problems cropped up, because the quality of the faculty, the conditions for setting up a school could not meet the parents' standards, they would spare no effort to solicit help through social connections for the sake of entering the key school. Actually, the situations of heavily over-students in key school haven't taken a favorable turn.

The state education department has proclaimed a policy, named "strengthen the weak links in schools construction". The official document put emphasis on plan to help every school in the city, and narrow down the gap between them. Another issue rose in front of us, how to improve the ill-equipped school. The society must increase the funding for education, at the same time, the amount of funding for education per year is limited. Thus, as long as we did so, the consequences were favored one side and discriminate against the other. It would take much energy, money to help an ordinary school become excellent. People would rather invest the money to key school for the bright future. Therefore, the present difficult plight was a discouragement to the action of strengthening the weak link in schools' construction, and the issue of school electing is still unsolved.

\subsubsection{Fairness in procedures}

It means to assure everyone receive good education, which is displayed by he disparities on some aspects, such as education funds, resources, contents, student-teacher relationship, impartial evaluations.

First of all, there exist the disparities in the educational resources distribution and the mode are not rational. This gap, in fact is determined by the economy development, and is the reflection in the area of education. Put it in concrete terms, the developed area has more financial strength to invest the education; on the other hand, it's difficult for the developing area to do so. Worse still, they are sometimes short of funds to meet the basic demand. In the family's respect, which refers to the expenses the families spend on education, people in developed area have a good income; few families' earn a low income, which stands for a small potation. Thus, the phenomenon of students' quitting school happens more frequently in under-developed countries than in economically advanced area. Meanwhile, the distributions of professional competence of the faculty are also irrational between areas. In the economically advanced, the education funds are well established, so the teachers' pay and benefits are attractive.

A large number of the teachers working at inland area are drawn to the coastal areas. Out of our expectation, in the poverty-stricken area, the phenomenon of losing of faculty is more aggravated, for the reason of the delayed wages of the teachers, Secondly, about the issue of teacher-student relationship. It is supposed to be democratic, equal, harmonious, jointed by the main line of affection. In reality, our teacher-student relationship isn't as the description above, the teachers stand for the supreme authority, while students should be obedient to them. Teachers' task is to repeat what the textbook says, with a stern expression everyday, as far as the students concerned, they do the same thing day after day, sitting in the line straightly, accepting the words as imperial edict totally and uncritically. If things go on like this, how could we deny the saying that out children are more and more servility? The problem lied in that when the teachers educate the students, they use the one-way means, instead of regarding them as persons of marked individuality, independence and potential capacities. The relationship between students and teachers is equal. Whether the teachers treat their students in cognitive approach, or respect their students' emotional experience, all these can adequately embody the concept of fairness in relationship between 
teachers and students.

Similarly, as to the problem of top students and the slow students, teaches' impaction is important. Education functions as the machine tool of working, it should be served for all the students, treat everyone the same. Presently, many schools and teachers are longing to be the good judge of talent, favoring to the students of great talent. Why the slow students have less chance to enjoy the benevolent action. The teachers are not the private tutor of the good student. They are in the face of a group that the good and the bad are intermingled.

A famous educator once proposed such a saying. He said, "the positive features of the slow students, to some degree, are not possessed by the top students, the reasons are as following: they can't digest what the teacher said, but they attend classes everyday; they encounter criticism everyday, but they meet with a smell everyday; they fail to past most of the exams, but they enter for the examination every time. This strong will power, which support than to rebound from a setback, is what the top students' lack, and many events have proved this to us, too many complimentary remark confused the top students who haven't taste the sense of frustration or depression. We have to admit that it's a drawback in our education ignoring the activation of EQ when we develop intellectual resources.

\subsubsection{Fairness in result}

It doesn't mean that the students will get to the same level after being educated, so does the achievement in studies, and the full development in each field. It mainly displayed the disparities in education among the different areas, also the backgrounds and opportunity of the students.

According to the related the research paper, when it comes to the social classes and family background, there still exists the difference of entering the key school and institution of higher learning. The disadvantage group lack choice, the sense of unfairness is increased by the gap of quality of education resources and requirements for admission. The children of the labor workers, who composed $90 \%$ of the population, are in a disadvantage position in front of the policy named everyone is equal before marks. On the other hand, children with the cadres and intellectuals background form a large proportion in the famous university and the popular specialties. Even being recruited by the college, and unpopular majors, such as the military academy, mainly admit the students from the poor area teacher-training school and agricultural colleges. It is in the key middle schools of the cities that the same phenomenon happens. Students from the cadres' and intellectuals' family take up a large part, far more than other social classes. Presently, the social are now focusing on the issue of "fairness in result". Essentially, it's the problem of the unfairness happened in college entrance examination. We adopt the national matriculation examination policy, thus we've already acquire the feature of fairness formally - everyone is equal before marks, meanwhile, we admitted students by means of quota system in separate provinces. But the policy gives priority to the city, instead of on the basis of the total students. Therefore, a strange phenomenon come up, the same paper, but the enrolment cut off point is greatly different, this situation widens the education gap between city and country.

More and more applicants to colleges and parents are not contented with the gap of the cut-off point was even lower than other provinces about hundred prints. This is a rigorously limitation to the students from other province to further continue studies in Beijing or Tianjin, where the universities crowd together. The so-called fair college entrance examination is unfair to examinee from the other parts of the country.

\section{Analyze the Issue}

\subsection{Theory of "Equality of education"}

Fairness of education has different definition in different times and social backgrounds. It's a conception with the features of dynamic, historical, regional, and this fairness can never be seen as static, historical and absolutely. Fairness of education has many meanings, but the theory "Equality of teaching", written by Thomason, a Sweden educationalist is adopted by most of the textbook and theoretical research. What is the Fairness in Wilson's theory? He believed that as far as the individual concerned, the fairness contains three meanings: first, fairness can refer to the starting point of an individual, everyone could begin his studying career without any limitation; second, fairness should also take place in the educational course, that is to say, the same treatment goes through the whole course, regardless of the human race nationality and social classes; third, it could also refers to the final goal, helping the students get the equality of opportunity to success in their studying .

On the basis of the theory, the educational practice goes closer with the guideline. Gradually, people form a common understanding on the definition of fairness of education.

On the whole, people divide the contents into three parts: First, fairness in starting point, which means that individual has the same opportunity to enter school, an everyone has the right to receive education, meanwhile, the country an the society should provide the basic condition to every child with the right age attending school. Second, fairness in process refers to the opportunity of receiving education should be equal; everyone owns the same chance to enter different educational department and get the same treatment in the process. Third, fairness in result refers to the opportunity of being success in their studying. This is on the strength of the fairness in starting point and process, in order to help the student's meet the latest standard.

Fairness of education owns different features in different educational stages. Generally people consider it from the 
elementary education and advanced education. On the aspect of advanced education, many countries still can't research it, only few countries begin to popularize it. As a result of this kind of education, so this paper is going to discuss the fairness of education from the point of elementary education.

The unfairness happened in the education is mainly determined by the economic development. The slow economic development leads to the inadequate education resources; and the unbalanced development in economy and cultural causes the urban -rural disparity, regional variations and poor-rich disparities; the concept of value sons and belittle daughter deprived the girls' education right more. The objective reality is formed with the history, therefore, the problem can be solved by the economic development and social advancement, and the reasons are as follow:

\subsection{The origin of the problem}

Trace the problem to its origin, all the unfairness stems from the unfairne in the economy. The country has made remarkable progress since 1980s. But on The general, it is unbalanced development, and this situation is more marked in the country, which is displayed by the low-level of the economy and development. When the coastal region in the eastern part developed commodity economy and township industry, their economy has developed rapidly, so has been the cultural and educational undertakings, while the central part and western part of China, the situation is the opposite. The agricultural operations in many areas are still in the state of infant farming. Their Economic power wouldn't permit them to invest more on education.

\subsection{The source of educational expenditure}

The source of educational expenditure in underdevelopment area is single. After 1985, our elementary education adopts the system of local government responsibility, level-to-level administration. Local governments at various Levels are directly accountable to the educational funds. Some township governments in poor area are unable to pool resource to support education, which aggravated the gap between areas. Generally speaking, the rich areas have more access to attract investment, such as the school-run factory, rises Funds to run schools, or donate money to build schools. On the contrary, the rural areas have no approach to these funds.

\subsection{The backward cultural value and ideology}

The backward thoughts are also the barrier for the development of education. It not only comes from the low productive forces, but also from the concept "a good scholar will make an official" formed in the feudal dynasty. At the same time, the locality in the countryside often perceived the educations as an individual behavior, illiteracy would not harm others. So it is unnecessary to enforce the nine-year compulsory education. In addition, the main reason for the girl dropout is the concept "value boys and belittle girls".

\subsection{The unbalanced distribution of education resources}

The unfairness lies in the unbalanced distribution of education resources. Now in the country, the distribution of the education resources tends to be unequal. The better schools they are, the more preference they got. Instead, the Worse the schools are, the more difficulties they meet. Therefore, the education distribution should consider two guidelines; one is that the rule should narrow down the gap; the other is that give more help to the backwardness. Besides, the key factor to the unfair distribution is the different attitude of the national education department to the higher education and elementary education. The society pool more educational funds to the higher education than any other country in the world. People think much of the higher education, and this embodies the concentration of efficiency. Things continue this way for a long time; the elementary education was placed at a disadvantage position. These realities go against with the educational fairness, and lower the quality of the population. Generally speaking, it's not a good omen for the economic development.

\subsection{The incorrectness in the educational policy}

The original will of the educational policies was good, but some had the Side effect of the unfairness. Take the college entrance examination for example, the gap in the cut-off point denies many students' opportunity to continue their studies. In addition, there are many other factors for the unfairness in the elementary education, such as the disparities existed in the quality of faculty, students' intelligence, the arrangement of the curriculum and the social backgrounds of the families.

\section{Suggestions about how to cope with the unfairness in education.}

As the above discussed, the fundamental education right the Chinese citizen enjoyed is "an unfair right" in substance. Therefore, it's the basic goal of the educational reform and development to accelerate the process of equalizing the education right.

In view of the existing situation, we can begin to solve the unfairness in the elementary education from the following aspects.

\subsection{Balance the educational resources}

As regards to the educational resources, there are three points. First of all, to make sure the financial power can support the educational funds. Give more expenditure to the poverty areas, in order to help them catch up with the standard, and reduce the gap between them. Secondly, establish the educational funds, and attract the education investment. The society should readjust the educational policy, and explore all possible sources of revenue, and further standardize the input in education, 
especially in the poverty-stricken areas. Meanwhile, the society should assist and encourage equalizing the distribution of the education resources. The new concept of the distribution is "Narrow down the gap during the development, increase the fairness"

\subsection{Improve the quality of the faculty}

As far as the human resources concerned, the society should strengthen the teachers' training, improve the quality of the faculty, and establish the democratic teacher-student relationship. The teachers are supposed to show care to all the children, give them the impartial treatments.

On the other hand, it's urgent to introduce the mechanism of discovering the people with talent. The schools can resort to some kinds of methods to reverse the strange situation, which the poor area lack teachers, while the college graduates are out-of-job. It's a better way to set up some incentive system by the state, in order to enhance the level of wages and benefits in the under-developed area.

Besides, the directional recruitment of students is also a practical scheme.

\subsection{Revamp the irrational system}

The educational policies are also concerned. First of all, revamp the irrational system. For example, overhaul the college entrance examination; cancel the different cut-off point in different areas. Local authorities should develop there education in line with their condition, and set up the clear stream of thought to infuse the locality concept, so as to be free of the hard and fast rule. Our aim is to reduce the disparities between the rural and the city by means of the educational system of educating young people in accordance with their special characteristics and the existing situation. Secondly, put priority on the development of the weak links in school construction, and change the situation of laying undue emphasis only on the key school. It is beneficial for us to learn from Japan and Korea educational reform, so as to push our education equalize. We can first realize the fairness in elementary school during the limited time as the first step, then step into the higher education gradually.

Once again, make sure the preference policy be established, and give assistance to the middle and western parts, so do the weak groups. The main point of third operation should popularize the nine-year compulsory education among the outlying villages and the minority nationality, narrow down the disparities in junior education between western and eastern, and increase the rate of universal junior high education in ethnic minority. We should attach importance to the education for the children of the floating population and low-income classes, and more important is to reach a practical solution of the education opportunity and fairness.

\section{Conclusion}

This paper is spread out from the point of the fairness of education in elementary education. As my paper described above, we still have a long way to go to realize the real fair education right to everyone. It will benefit not only the individual, but the whole society. Thus to cultivate the sense of fairness of education is the main task of the education reform now. May this paper will do some help to the existing situation.

\section{References}

Guo Yuanxiang. (2002). The thought of the fairness in education, People Educational Press.

Min Jing, \& Li Jinyu. (2002). The reform of the curriculum in western part, Foreign Language Teaching and Research Press.

Husén, T. \& Postlethwaite, TV (Ecs.). (1994). The International Encyclopedia of Education. 2nd ed.Vol.3.Oxford: Pergamon Press, 12. 